\title{
AVALIAÇÃO DE EMPRESAS: ASPECTOS OBJETIVOS NA VERIFICAÇÃO DE VALOR ECONÔMICO DE ATIVOS INTANGÍVEIS*
}

\section{COMPANY VALUATION: OBJECTIVES ASPECTS IN THE VERIFICATION OF ECONOMIC VALUE OF INTANGIBLES ASSETS}

\author{
NIVALDO JOÃO DOS SANTOS \\ Doutor em Engenharia de Produção pela Universidade Federal de \\ Santa Catarina (UFSC). Contador, Sócio-Diretor de Peritia Contadores \\ Associados S/S. Endereço: Rua Araújo Figueiredo, 119, sala 1104 / \\ Centro | 88010-520 | Florianópolis/SC | Brasil. \\ E-mail: nivaldo@peritiacontadores.com.br
}

\begin{abstract}
RESUMO
Neste artigo discute-se aspectos objetivos na determinação de valor econômico para os elementos intangíveis criados pela empresa. Tais elementos, abrigados sob a denominação de capital intelectual, goodwill, ou fundo de comércio, são representados pela marca, pelo bom atendimento aos clientes e pela localização privilegiada do negócio, dentre outros. Trata-se de estudo de caso de avaliação de empresa e negócio dentro da indústria automotiva, localizada na Região Sul do Brasil, envolvendo determinação judicial. Os procedimentos metodológicos envolveram a avaliação econômica da empresa sob dois aspectos: a) como um conjunto de elementos patrimoniais e b) como um negócio gerador de saldos de caixa livre ao longo dos anos. Foi evidenciado que o refinamento das informações sobre os ativos operacionais e a adequada compreensão dos custos e despesas pertinentes ao negócio em particular é indispensável para a determinação do justo valor da empresa e oferece mais objetividade ao cálculo do valor econômico referente ao conjunto de elementos intangíveis criados.
\end{abstract}

Palavras-chave: Avaliação de empresas. Capital intelectual. Avaliação de goodwill. Fundo de comércio. Ativos intangíveis.

\begin{abstract}
This article discusses objective aspects in determining economic value to the intangible assets created by the company. Such assets, housed under the name of intellectual capital or goodwill, are represented by the brand, the good customer service and the prime location of business, among others. This is a case study of company and business valuation within the auto industry, located in southern Brazil, involving judicial determination. The methodological procedures involved the economic valuation of the company in two ways: a) as a set of equity assets and b) as a business generator of free cash flow over the years. It was shown that the refinement of information about the operating assets and the proper understanding of the relevant costs and expenses to particular business are essential for determining the fair value of the company and offers more objectivity to the calculation of the related economic value to the set of intangibles assets created.
\end{abstract}


Keywords: Company valuation. Intellectual capital. Goodwill valuation. Goodwill. Intangibles assets.

\section{INTRODUÇÃO}

A avaliação econômica de empresas de capital fechado é atividade complexa, geralmente requisitada a profissionais experientes. Muitas vezes apresenta-se com números discutíveis e, não raro, termina submetida à decisão judicial. Em parte, segundo Ornelas (2003), tal situação decorre da fragilidade da fonte de informações para o trabalho de avaliação, essencialmente originária do sistema contábil das empresas, especialmente quando se trata de empresas de pequeno e de médio portes (PMEs). Tal contingente de sociedades mercantis, de uma forma geral, não possui sistema contábil suficientemente estruturado para responder com eficiência às demandas de informações e de dados requisitados pelos trabalhos envolvendo avaliação de empresas.

Um importante fator de geração de controvérsias acerca dos resultados das avaliações refere-se ao valor atribuído, ou à sua falta, aos elementos intangíveis criados, denominados capital intelectual, goodwill, ou fundo de comércio, os quais se percebem pela marca, nome comercial, bom atendimento aos clientes, localização privilegiada e pelo know how. Em relação a tais elementos, os sócios retirantes, herdeiros, viúvas e procuradores nutrem grandes expectativas, no sentido de serem aquinhoados com elevadas quantias. Tal expectativa nem sempre se concretiza. Em grande parte, essa esperança é alimentada pela farta literatura do campo da gestão empresarial e do direito societário, que, por vezes, exacerbam a importância econômica dos tais elementos intangíveis, sem, contudo, associá-los com a lucratividade do negócio, e ausentes de vinculação com os ativos, faturamento e lucro (Damodaran, 2007).

O propósito deste artigo é discutir aspectos objetivos na determinação de valor econômico para os elementos intangíveis criados pela empresa, no âmbito do processo de avaliação de sociedades de capital fechado, especialmente as de pequeno e médio porte (PME). A contribuição principal deste estudo consiste em reunir e sintetizar conceitos e demonstrar uma alternativa fundamentada e voltada ao cálculo do fundo de comércio ou goodwill. A importância de iniciativas dessa natureza consiste principalmente em aproximar e relacionar o embasamento teórico com a observação da realidade.

\section{REVISÃO DA LITERATURA}

A seguir são apresentados os principais conceitos e discussões teóricas utilizados nas aplicações práticas deste trabalho, especificamente a avaliação de empresas pelas abordagens dos ativos e da renda, determinação da taxa de desconto, o conceito de valor econômico do negócio e a questão dos intangíveis criados, denominados fundo de comércio ou goodwill.

\subsection{Elementos intangíveis}

Em relação ao patrimônio da empresa um ativo intangível deve ser identificável e não pode ser confundido com o ágio derivado da expectativa de rentabilidade futura do negócio, denominado goodwill, conforme preceitua o Pronunciamento Técnico CPC 04 (R1) (Comitê de Pronunciamentos Contábeis, 2010).

Diversos elementos intangíveis são criados ao longo da existência da empresa e eventualmente tornam-se benefícios econômicos, tais como nome comercial, marca, lista de clientes, equipe de empregados treinada, localização privilegiada (ponto), dentre outros. Tal conjunto de atributos também é denominado goodwill ou fundo de comércio (Santos, 2011). Todavia, não são reconhecidos nas demonstrações financeiras, a menos quando adquiridos (Churyk \& Mantzke, 2008).

O direito empresarial brasileiro, especificamente o Código Civil, Lei oㅜ10.406/2002, Artigo 1.031, dispõe que na avaliação de uma empresa, para fins de liquidação da participação societária, há que se considerar a totalidade dos bens corpóreos e incorpóreos, adquiridos ou criados, demonstrados por meio de balanço especialmente levantado. Para Sá (2000), os elementos intangíveis resultam do aumento de funções do próprio capital material e dos agentes que sobre o mesmo atuam para dinamizá-lo e aumentar a capacidade de utilidade ou eficácia, 
em prol do negócio. Sobre a complexidade da mensuração isolada de elementos intangíveis criados, Clarkson (2000) afirma que possivelmente a contabilização de elementos intangíveis identificáveis não oferece tanta insegurança quanto a avaliação isolada do capital intelectual, conceituado como um abrangente conjunto de fatores da criação humana.

Segundo Watson (2010), muitos autores reputam a avaliação monetária individualizada de intangíveis como um esforço com benefícios discutíveis. Considerando que os valores não podem ser retratados em demonstrações contábeis, não são aceitos como garantia de empréstimos e investidores se interessam essencialmente pelas sobras líquidas de caixa que o negócio pode prover.

Com o propósito de avaliar a opinião das pessoas sobre a importância dos componentes do capital intelectual dentro de suas organizações, Axile-Ortiz (2013) realizou levantamento baseado em testes de atitudes e concluiu que a percepção do valor econômico dos componentes do capital intelectual varia em magnitude, dependendo do contexto, o que é determinado pela área geográfica em que atua, o setor da indústria, as particularidades operacionais e o tamanho da organização.

O citado autor afirma que somente os seres humanos podem desenvolver os ativos intangíveis. A única maneira possível de gerenciá-los é pela consciência de sua composição e pelo reconhecimento do seu valor na organização. Eles são intrínsecos ao ser humano. As empresas não podem incorporá-los como agentes externos, transferi-los, empacotá-los, comercializá-los ou comprá-los isoladamente.

O estabelecimento empresarial, constituído de elementos patrimoniais tangíveis, por si só, não é a fonte de criação e sustentação de valor para o capital intelectual. Os elementos intangíveis são criados, fortalecidos ou destruídos pela dinâmica ou giro do negócio, conforme ilustrado na Figura 1.

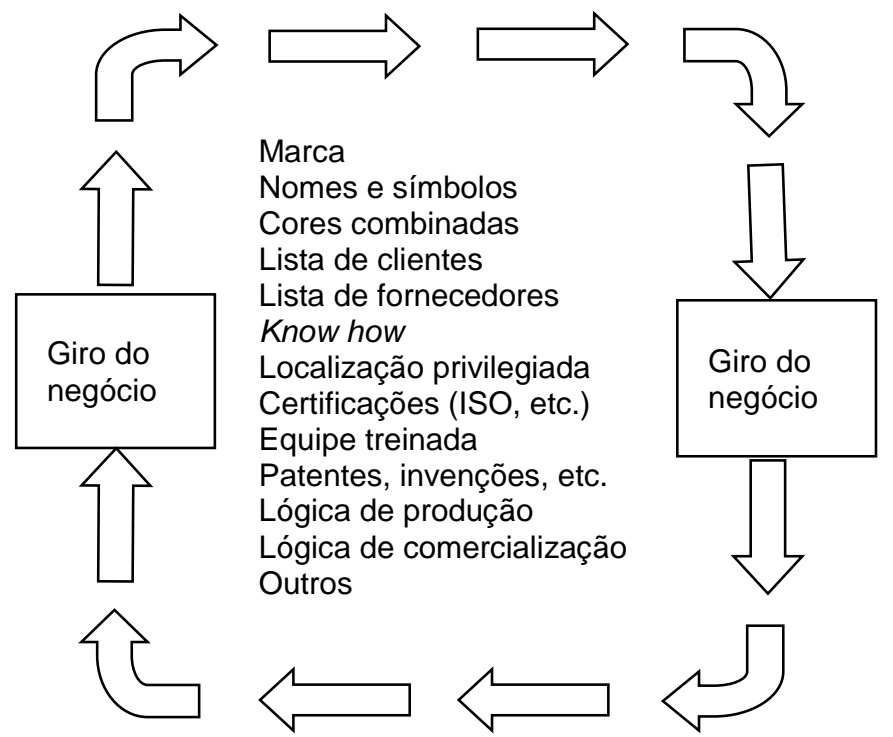

Figura 1. Criação e fortalecimento dos elementos intangíveis Fonte: Elaborada pelo autor.

A maioria dos elementos intangíveis que impulsionam a rentabilidade da empresa é criada pelo desenvolvimento do negócio próspero e possui forte inter-relacionamento entre si (Chareonsuk \& Chansa-ngavej, 2010). Em função dessa dependência, grande parte dos elementos intangíveis desaparece ou perde expressão monetária se a empresa entrar em processo falimentar. Nessa condição, a marca e o nome ficam estigmatizados perante o mercado, a lista de clientes se esvazia, os fornecedores ficam receosos em vender e, naturalmente, o quadro de empregados se dissolve e segue carreira em outras empresas. Essa movimentação compromete as sinergias e vantagens empresariais sedimentadas ao longo dos anos.

Negócios pouco rentáveis ou deficitários não direcionam expressão monetária aos elementos intangíveis criados, porque esses emergem economicamente a partir de lucros. É 
oportuno ressaltar que os lucros de um negócio eficiente devem ser superiores aos dos rendimentos provenientes dos ativos corpóreos, caso esses sejam liquidados e aplicados em ativos financeiros de baixo risco.

\section{2 abordagens de avaliação de empresas}

As metodologias e abordagens de avaliação de empresas mais citadas são: avaliação com base no valor dos ativos, avaliação com base no valor da renda, avaliação com base em múltiplos de transações comparáveis e avaliação com base em opções. Segundo Rabianski (1996), a avaliação de uma empresa em continuidade ou em marcha (going concern) deve refletir o valor dos imóveis, máquinas e equipamentos, capital de giro e todos os outros ativos que contribuem para a exploração do negócio, incluídos os elementos intangíveis criados. Para efeitos dessa revisão, o foco de discussão ficará circunscrito às avaliações com base nos ativos e na renda do negócio.

\subsubsection{Avaliação com base no valor dos ativos}

Segundo Harris (1997), as formas de mensurar monetariamente os ativos que mais se destacam são: avaliação com base no valor patrimonial; avaliação com base no valor patrimonial ajustado; avaliação com base no valor de reposição (replacement); avaliação com base no valor de liquidação. O método do valor patrimonial é o mais simples das avaliações (Robert, 2006). Hawkins (2002) explica que o ponto fraco do método do valor patrimonial é a sua subordinação às normas contábeis, especificamente àquelas que orientam para os registros das operações pelo seu custo histórico.

$\mathrm{Na}$ avaliação com base no valor patrimonial ajustado é necessário revisar e ajustar os elementos patrimoniais, inclusive para determinar o valor real dos bens intangíveis, tais como ágio e patentes. Eventuais registros de valor de goodwill e de prêmio pela aquisição também devem ser examinados, e expurgados, com o propósito de tornar o valor do balanço especial mais realista (Robert, 2006).

No método da avaliação com base no valor de reposição (replacement), também referido como método do custo de reposição depreciado, o ativo é valorado pelos custos necessários à sua aquisição ou reprodução, descontada a depreciação. A depreciação é definida a partir da expectativa de vida útil remanescente do bem (Harris, 1997; Lorenz \& Lützkendorf, 2008).

A avaliação com base no valor de liquidação adota o valor de mercado e consiste em determinar os valores de balanço em termos de importâncias líquidas que seriam alcançadas em uma venda rápida ou venda forçada (Robert, 2006). Helfert (2000) adverte que a adoção do método do valor de liquidação aplica-se a uma situação anormal, influenciada por pressões do tempo e de outras restrições, como no caso de venda de bens de massa falida.

O novo Código de Processo Civil brasileiro, Lei no 13.105/2015, art. 606, que passou a vigorar em março de 2016, estabelece critério para a indenização de participações societárias a sócio retirante, ao determinar que serão avaliados "os bens e direitos do ativo, tangíveis e intangíveis, a preço de saída, além do passivo também a ser apurado de igual forma". Além disso, demonstrou preocupação com a competência do avaliador ao determinar que a "nomeação do perito recairá preferencialmente sobre especialista em avaliação de sociedades".

Ao avaliar uma empresa considerando somente o acervo identificado, o perito avaliador despreza o conhecimento da expressão monetária de elementos formadores do capital intelectual, tais como reputação do negócio (goodwill), marca, sinergias empresariais e outros intangíveis criados. Para evitar tal parcialidade na avaliação da empresa faz-se necessária a determinação do valor econômico do negócio.

\subsubsection{Avaliação com base no valor da renda}

No entendimento de Leitner (2005), o valor de uma empresa de capital fechado se baseia no retorno sobre o capital investido e na percepção do mercado sobre o seu futuro. Para Verginis \& Taylor (2004), a abordagem da capitalização da renda captura melhor o valor de uma sociedade do que qualquer outra abordagem. Dois métodos de avaliação de empresas são mais empregados, quando se trata de determinar rendas futuras: avaliação com base no valor do fluxo 
de caixa livre descontado e avaliação com base no valor dos dividendos. Neste estudo a discussão focará a avaliação com base no fluxo de caixa livre descontado.

Segundo Luerhman (2006), Robert (2006), o método do fluxo de caixa descontado (FCD) é um processo de apuração de valores em que os futuros fluxos de caixa livres, incluindo o valor residual dos ativos, são convertidos a valor presente, utilizando uma taxa de desconto.

Outro ponto fundamental na aplicação do método do FCD refere-se à definição da taxa de desconto. Clarkson (2000) afirma que o custo de capital da empresa é representado pelo custo individual das fontes de capital, ponderados de acordo com sua importância na estrutura de capital da empresa.

Numa simplificação conceitual, Ross, Westerfield \& Jaffe (2007) afirmam que a taxa de desconto é uma espécie de taxa de juros usada para descontar fluxos de caixa ao seu valor presente e que deve ser aquela que melhor reflita o custo de oportunidade e os riscos.

\section{METODOLOGIA}

Este trabalho caracteriza-se como de estudo de caso. Trata da avaliação de empresa e negócio dentro da indústria automotiva, localizada na Região Sul do Brasil, envolvendo determinação judicial. Os procedimentos metodológicos para avaliação da empresa objeto do presente estudo de caso basearam-se na sistemática descrita por Santos (2011).

Fruto de pesquisa em relatórios de avaliação de empresas, a sistemática consiste na reunião e sintetização de conceitos acerca de avaliação de negócios e empresas, compatibilizando as providências avaliatórias com as normas do direito de empresas vigentes no Brasil, especificamente aquelas preconizadas pelo Código Civil e pelo Código de Processo Civil brasileiro. Ainda, segundo Santos (2011), a busca pelos elementos que contribuem para a determinação do valor da empresa revelou três aspectos fundamentais que deverão ser examinados isoladamente. Tais aspectos são:

a) Relações de sociedade: esse aspecto trata do exame e consideração das disposições contratuais ou estatutárias; das datas dos eventos (exclusão, retirada ou óbito); dos adiantamentos e empréstimos de sócios, bem como se orienta pelos principais ordenamentos jurídicos e contábeis para determinação de haveres de sócio ou acionista.

b) Estabelecimento empresarial: o estabelecimento empresarial abriga os elementos patrimoniais tangíveis e intangíveis, adquiridos ou criados pela empresa, tais como disponibilidades, créditos a receber, estoques, imóveis, máquinas, equipamentos, marcas e direitos de uso, dentre outros. Tais elementos dão o suporte para a realização ou exploração do negócio.

c) Negócio: trata-se do objeto que a sociedade propõe-se a empreender, operar ou explorar, com o propósito de gerar proveito econômico. É o negócio que cria ou destrói valor para o sócio ou acionista. O critério de avaliação do negócio se baseia na mensuração da expectativa de lucros (renda).

Para determinar o valor da empresa deverá ser procedida a avaliação dos elementos patrimoniais (Ativos) e a mensuração da expectativa de lucros, benefícios e proveitos do negócio, compreendidos em termos de geração de caixa livre. A Tabela 1 enumera as atividades para determinação do valor da empresa e participações societárias.

Tabela 1

Atividades para determinação do valor da empresa e participações societárias Especificação

\begin{tabular}{l|ll}
\hline 1 & Definição da data base & \\
\hline 2 & Identificação dos bens e direitos & \\
\hline 3 & Avaliação dos bens e direitos identificados & Continua
\end{tabular}


Tabela 1 (continuação)

\begin{tabular}{c|l}
\hline \multicolumn{2}{c}{ Especificação } \\
\hline 4 & Identificação dos ativos não operacionais \\
\hline 5 & Mensuração do potencial de lucros e sobras líquidas de caixa \\
\hline 6 & Determinação do valor econômico da empresa \\
\hline 7 & Mensuração do goodwill ou fundo de comércio \\
\hline 8 & Identificação e mensuração de dívidas e obrigações da empresa \\
\hline 9 & Elaboração do balanço de determinação ou especial \\
\hline 10 & Determinação do valor das quotas ou lote de ações \\
\hline
\end{tabular}

Nota. Fonte: Adaptada de Santos. N. J. (2011) Metodologia para determinação do valor econômico de empresas de capital fechado em processos de apuração de haveres de sócio. Tese de Doutorado em Engenharia de Produção, Universidade Federal de Santa Catarina (UFSC), Florianópolis, SC, Brasil.

1) Definição da data base: o valor de uma empresa é específico para determinada data. A data base ou data da avaliação é o ponto temporal, delimitador cronológico da existência do acervo patrimonial.

2) Identificação dos bens e direitos: refere-se à atividade de inventário dos bens tangíveis e intangíveis, suscetíveis de expressão monetária objetiva, que serão submetidos à avaliação.

3) Avaliação dos bens, direitos e dívidas identificados: a avaliação dos elementos patrimoniais deve adotar critérios de mensuração monetária diferenciados, contemplando a sua tipologia e as características operacionais. A Tabela 2 apresenta as diretrizes ou critérios para a avaliação dos bens, direitos, dívidas e obrigações.

Tabela 2

\section{Critérios de avaliação dos elementos patrimoniais}

\begin{tabular}{l|l}
\hline \multicolumn{1}{c|}{ Elementos patrimoniais } & \multicolumn{1}{c}{ Critérios de avaliação } \\
\hline Caixa e equivalentes de caixa & Vens e direitos \\
\hline Créditos & Valor contábil. \\
\hline \multirow{2}{*}{ Estoques } & $\begin{array}{l}\text { Valor de mercado deduzido das despesas de } \\
\text { comercialização. }\end{array}$ \\
\hline Despesas de exercícios seguintes & Valor contábil. \\
\hline Investimentos & $\begin{array}{l}\text { Valor contábil, valor da equivalência patrimonial ou valor } \\
\text { de mercado. }\end{array}$ \\
\hline \multirow{2}{*}{ Imobilizado } & Terrenos - valor de mercado. \\
\cline { 2 - 2 } & $\begin{array}{l}\text { Edificações, móveis e equipamentos - Valor de } \\
\text { reprodução (replacement) ou mercado. }\end{array}$ \\
\hline Intangível & Valor econômico. \\
\hline Leasing financeiro & Custo. Registrar as parcelas a pagar como dívida. \\
\hline
\end{tabular}

Dívidas e obrigações

\begin{tabular}{l|l}
\hline $\begin{array}{l}\text { Fornecedores a pagar, impostos a recolher e salários a } \\
\text { pagar }\end{array}$ & Valor contábil. \\
\hline Empréstimos e financiamentos a pagar & $\begin{array}{l}\text { Valor presente, como se fossem liquidados na data da } \\
\text { avaliação. }\end{array}$ \\
\hline Riscos tributários, trabalhistas e cíveis & Valor com base em levantamentos específicos. \\
\hline
\end{tabular}

Nota. Fonte: Adaptada de Santos. N. J. (2011) Metodologia para determinação do valor econômico de empresas de capital fechado em processos de apuração de haveres de sócio. Tese de Doutorado em Engenharia de Produção, Universidade Federal de Santa Catarina (UFSC), Florianópolis, SC, Brasil.

4) Identificação dos ativos não operacionais: Devem ser segregados os bens e direitos que não possuem influência na geração de receitas operacionais, tais como: imóveis arrendados, equipamentos e instalações redundantes sem justificativa, dentre outros. 
Para efeitos da avaliação da empresa, tais bens podem ser disponibilizados à venda imediatamente (Damodaran, 2007).

5) Mensuração do potencial de lucros e sobras líquidas de caixa: compreende a estimativa de faturamento, custos, despesas, impostos e sobras líquidas de caixa, com emprego da metodologia do fluxo de caixa descontado, que se resume na seguinte expressão:

Lucro antes dos juros e impostos (EBIT)

(-) Impostos sobre o lucro

(+) Depreciação e outros encargos que não envolvem saídas de caixa

(-) Necessidade de capital de giro adicional

(-) Gatos com ampliação ou reposição de ativos (CAPEX - capital expenditure)

$(+)$ Valor residual dos ativos

= Fluxo de caixa livre

A taxa de desconto dos ganhos futuros deve ser estipulada com anuência dos sócios e partes interessadas, de maneira que variáveis possam ser encontradas sem grandes dificuldades. Santos (2011) propõe a seguinte fórmula:

$T D=(I+R+P) \times(1-T)$

Em que:

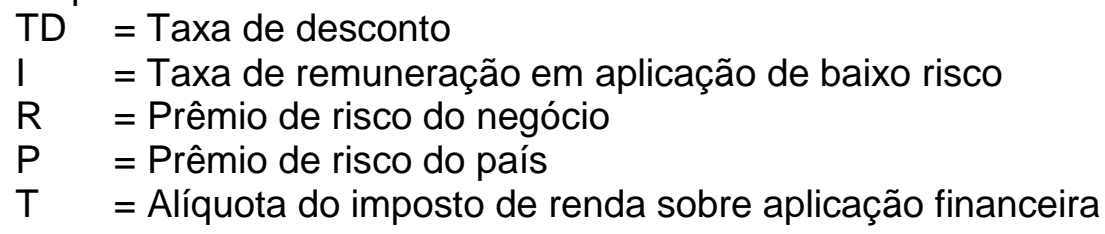

A taxa resultante dessa fórmula refere-se exclusivamente à expectativa de remuneração do capital próprio. Isso se justifica porque nessa metodologia de avaliação as dívidas e obrigações da empresa são consideradas pelo seu valor na data da avaliação, conforme dispõe a Lei $n^{0} 13.105 / 2015$. Portanto, não importa o custo do capital de terceiros.

6) Determinação do valor econômico da empresa: é composto de elementos específicos identificados e mensurados anteriormente, conforme segue.

Potencial de lucros e sobras líquidas de caixa

(+) Caixa e equivalentes de caixa

(+) Ativos não operacionais

(=) Valor econômico da empresa

O valor econômico encontrado nessa expressão deverá ser confrontado com o valor dos elementos patrimoniais avaliados e adotado, como valor da empresa, o maior.

7) Mensuração do goodwill: o valor do ativo intangível criado - goodwill ou fundo de comércio - está contido no valor econômico da empresa. Tal expressão monetária é obtida pela diferença entre o valor econômico da empresa e o valor dos ativos identificados avaliados.

Valor econômico da empresa

(-) Valor dos ativos identificados e avaliados

= Valor do goodwill 
$\mathrm{Na}$ situação em que o valor dos elementos patrimoniais ativos identificados se revelar igual ou maior do que o valor econômico da empresa, diz-se, então, que não há expressão monetária para o fundo de comércio ou goodwill.

8) Identificação e mensuração de dívidas e obrigações da empresa: Na sistemática em apresentação as dívidas e obrigações são identificadas e valoradas como se fossem liquidadas na data base da avaliação da empresa.

9) Elaboração do balanço de determinação: trata-se de balanço patrimonial específico, que conterá:

Valor dos ativos identificados e avaliados

(+) Elementos intangíveis criados (goodwill)

(-) Dívidas e obrigações

= Situação líquida, corresponde à totalidade do valor das participações societárias

10) Determinação do valor das quotas ou lote de ações: o valor da participação societária individual será calculado em função do percentual do capital que o sócio retirante possuir.

\section{AVALIAÇÃO ECONÔMICA DA EMPRESA GAMA - ESTUDO DE CASO}

O caso apresentado a seguir refere-se a uma situação real de avaliação de empresa, elaborada em atendimento à determinação judicial. A Empresa Gama era um dos ativos que constituíam a massa falida de um grupo empresarial. Na data da avaliação estava operando normalmente, e em plena capacidade, mas deveria ser vendida para quitar dívidas dos falidos. O nome da empresa bem como os valores envolvidos estão descaracterizados por questões de confidencialidade.

\subsection{Procedimentos de avaliação}

A empresa Gama é uma sociedade de capital fechado, de médio porte, Foi constituída em 1978 e está localizada em Santa Catarina, Região Sul do Brasil. O seu negócio é prover soluções em projetos e tecnologia no mercado de termofixos e termoplásticos, destinadas principalmente à indústria automotiva.

As premissas e diretrizes de avaliação foram definidas pelo perito avaliador, ouvindo os diretores e executivos da empresa, conforme apresentadas na Tabela 5, adiante. Com base nos dados fornecidos e informações prestadas pela Empresa Gama foram realizados os procedimentos e os cálculos preconizados na sistemática da avaliação econômica de empresas, disposta em Santos (2011):

1) Definição da data base: a data base da avaliação da empresa foi definida como 31/03/2016, ocasião do início dos trabalhos avaliatórios.

2) Identificação dos bens e direitos: o procedimento de identificação do acervo de bens e direitos adotou o balancete elaborado à data base, recebeu dados administrativos e de setores da produção para completar o inventário.

3) Avaliação dos bens e direitos identificados: os elementos constantes do balancete contábil foram revisados e avaliados, respeitando as diretrizes e critérios apresentados na Tabela 2. A revisão dos valores consistiu na confirmação da existência do bem ou direito e da verificação da capacidade de realização em dinheiro do elemento patrimonial. Após tais procedimentos, foi elaborado o balanço patrimonial especial, apresentado na Tabela 3. 
Tabela 3

Balanço patrimonial especial - Empresa Gama - \$1,00

\begin{tabular}{l|r|l|r}
\multicolumn{1}{c|}{ Ativo } & \multicolumn{1}{c|}{ Valor } & \multicolumn{1}{c}{ Passivo } & Valor \\
\hline Ativo circulante & $\mathbf{4 2 . 5 4 8}$ & Passivo circulante & $\mathbf{2 5 . 2 6 3}$ \\
\hline Caixa e equivalentes de caixa & 18.260 & Fornecedores a pagar & 15.372 \\
\hline Contas a receber de clientes & 12.450 & Impostos a pagar & 9.891 \\
\hline Impostos a recuperar & 3.219 & Passivo não circulante & $\mathbf{2 6 . 8 1 1}$ \\
\hline Outros valores a realizar & 1.891 & Impostos parcelados & 9.432 \\
\hline Estoques & 6.564 & Financiamentos a pagar & 17.379 \\
\hline Despesas de exercícios seguintes & 163 & & \\
\hline Ativo não circulante & $\mathbf{5 2 . 2 4 8}$ & Situação líquida & $\mathbf{4 2 . 7 2 2}$ \\
\hline Realizável a longo prazo & $\mathbf{4 . 6 4 0}$ & & \\
\hline Créditos realizáveis a longo prazo & 3.171 & & \\
\hline Depósitos compulsórios & 1.469 & & \\
\hline Investimentos & $\mathbf{1 2}$ & & \\
\hline Imobilizado & $\mathbf{4 7 . 5 9 6}$ & & \\
\hline Terrenos & 19.184 & & \\
\hline Edificações e benfeitorias & 12.468 & & \\
\hline Veículos & 83 & & \\
\hline $\begin{array}{l}\text { Máquinas, equipamentos, } \\
\text { instalações, móveis e utensílios }\end{array}$ & 15.861 & & \\
\hline Total do ativo & $\mathbf{9 4 . 7 9 6}$ & Total do passivo & \\
\hline No Fon.796 \\
\hline
\end{tabular}

Nota. Fonte: Elaborada pelo autor com dados modificados da empresa Gama.

4) Identificação dos ativos não operacionais: os créditos realizáveis a longo prazo, o investimento em ações e uma parte do terreno da Unidade de Produção II foram tratados como ativos não operacionais. Esse entendimento foi alcançado após a análise da essencialidade desses ativos para a consecução de receitas operacionais oriundas do negócio explorado.

Tabela 4

Ativos não operacionais - Empresa Gama - \$1,00

\begin{tabular}{lr}
\multicolumn{1}{c|}{ Descrição } & \multicolumn{1}{c}{ Valor $\mathbf{R} \mathbf{\$}$} \\
\hline Créditos realizáveis a longo prazo & 3.171 \\
\hline Depósitos compulsórios & 1.469 \\
\hline Investimentos em ações & 12 \\
\hline Parte terreno Unidade II - Fábrica de Compostos & 3.623 \\
\hline
\end{tabular}

Nota. Fonte: Elaborada pelo autor com dados modificados da empresa Gama.

5) Mensuração do potencial de lucros e sobras líquidas de caixa: essa parte da avaliação compreendeu as seguintes atividades:

- análise crítica das receitas, custos e despesas;

- definição da taxa de crescimento das receitas e horizonte de projeções;

- identificação da forma de tributação do lucro;

- exame de conformidade de documentos e livros contábeis;

- identificação da necessidade de capital de giro adicional;

- identificação da necessidade de reposição e ampliação do ativo imobilizado;

- determinação do valor terminal ou residual do ativo imobilizado;

- definição da taxa de desconto.

Foi definido em consenso com os gestores da empresa um conjunto de informações, premissas e diretrizes para compor o fluxo de caixa descontado (FCD), conforme consta da Tabela 5. 
Tabela 5

Informações, premissas e diretrizes para compor o FCD

\begin{tabular}{l|c}
\multicolumn{1}{c|}{$\quad$ Especificação } & Dado/Informação \\
\hline EBIT 2016 & $\$ 16.650$ \\
\hline EBIT 2017 & $\$ 17.775$ \\
\hline EBIT 2018 & $\$ 19.725$ \\
\hline EBIT 2019 & $\$ 20.130$ \\
\hline Horizonte de projeção & Lucro real \\
\hline Forma de tributação do lucro & $\$ 2.122$ \\
\hline Depreciação/ Amortização alocadas ao custo e despesas & $34 \%$ \\
\hline Taxa do Imposto de renda e contribuição social sobre o lucro líquido & Sem ressalvas \\
\hline Conformidade de documentos e livros contábeis & $\$ 469$ \\
\hline Necessidade de capital de giro adicional 2016 & $\$ 869$ \\
\hline Necessidade de capital de giro adicional 2017 & $\$ 197$ \\
\hline Necessidade de capital de giro adicional 2018 & 0 \\
\hline Necessidade de capital de giro adicional 2019 & 0 \\
\hline Necessidade de reposição e ampliação de ativos & $17,10 \%$ \\
\hline Valor terminal ou residual dos ativos &
\end{tabular}

Nota. Fonte: Elaborada pelo autor com dados modificados da empresa Gama.

A projeção de receitas operacionais considerou crescimento das vendas nos anos de 2017, 2018 e 2019, com fundamento no estudo setorial encomendado pelo perito avaliador. Não foram considerados novos ganhos de produtividade ou de economias por eficiência produtiva.

Para estabelecimento da taxa de desconto foi adotada a taxa de rendimento de títulos do Governo brasileiro (SELIC), majorada em 50\%, correspondendo ao prêmio de risco do negócio. O percentual correspondente ao risco país foi considerado implícito na referida taxa SELIC.

O cálculo do fluxo de caixa descontado foi realizado em dois procedimentos. O primeiro consistiu em reunir os valores que geram caixa livre nos períodos, conforme mostra a Tabela 6. O segundo procedimento compreendeu o cálculo do valor presente desses caixas livres, utilizando a taxa de desconto estipulada em 17,10\%.

Tabela 6

Cálculo do fluxo de caixa livre - $\$ 1,00$

\begin{tabular}{|c|c|c|c|c|}
\hline Especificação & 2016 & 2017 & 2018 & $\begin{array}{l}2019 \\
\text { em diante }\end{array}$ \\
\hline EBIT & 16.650 & 17.775 & 19.725 & 20.130 \\
\hline $\begin{array}{l}\text { (-) Imposto de renda e contribuição } \\
\text { social sobre o lucro líquido }\end{array}$ & $(5.661)$ & $(6.044)$ & $(6.707)$ & $(6.844)$ \\
\hline (+) Depreciação do imobilizado & 2.122 & 2.122 & 2.122 & 2.557 \\
\hline $\begin{array}{l}\text { (-) Reposição e ampliação de ativos } \\
\text { (CAPEX) }\end{array}$ & $(2.557)$ & $(2.557)$ & $(2.557)$ & $(2.557)$ \\
\hline $\begin{array}{l}\text { (-) Necessidade de capital de giro } \\
\text { adicional }\end{array}$ & $(469)$ & $(869)$ & $(197)$ & - \\
\hline Fluxo de caixa livre & 10.085 & 10.427 & 12.386 & 13.286 \\
\hline
\end{tabular}

Nota. Fonte: Elaborada pelo autor com dados modificados da empresa Gama.

Conforme especificado na Tabela 7, a seguir, foram traduzidos a valor presente os saldos finais de caixa nos períodos projetados. A partir do quarto ano o valor da depreciação foi igualado ao valor do CAPEX. Também a partir do quarto ano os valores foram transformados em perpetuidade, que também é compreendida como o valor residual ou terminal dos ativos operacionais empregados na geração de caixa. 
Tabela 7

Fluxo de caixa descontado - \$1,00

\begin{tabular}{|c|c|c|c|c|}
\hline Especificação & 2016 & 2017 & 2018 & $\begin{array}{c}2019 \\
\text { em diante }\end{array}$ \\
\hline Fluxo de caixa livre & 10.085 & 10.427 & 12.386 & 13.286 \\
\hline Fator de desconto & 0,89 & 0,76 & 0,65 & 3,79 \\
\hline Fluxo de caixa descontado & 8.959 & 7.910 & 8.024 & 50.334 \\
\hline
\end{tabular}

Nota. Fonte: Elaborada pelo autor com dados modificados da empresa Gama.

6) Determinação do valor econômico da empresa: com base nos valores encontrados nas providências anteriores foi estabelecido o valor econômico da empresa. A Tabela 8 apresenta os elementos que compõem tal valor.

Tabela 8

Valor econômico da empresa $-\$ 1,00$

\begin{tabular}{l|r}
\multicolumn{1}{c|}{ Especificação } & \multicolumn{1}{c}{ Valor } \\
\hline Potencial de lucros e sobras líquidas de caixa & 75.227 \\
\hline Caixa e equivalentes de caixa & 18.260 \\
\hline Ativos não operacionais & 8.274 \\
\hline Valor econômico da empresa & 101.762 \\
\hline
\end{tabular}

Nota. Fonte: Elaborada pelo autor com dados modificados da empresa Gama.

Ressalte-se que ao adotar a abordagem da renda para avaliar a participação societária, com uso da metodologia do fluxo de caixa descontado, o avaliador não está atribuindo lucros futuros ao sócio retirante ou ao vendedor da empresa. O fluxo de caixa descontado cumpre a tarefa de mensurar os benefícios e proveitos monetários decorrentes de um negócio lucrativo deixado para os sócios adquirentes ou remanescentes.

7) Mensuração do goodwill ou fundo de comércio: é determinada pela diferença entre o valor econômico da empresa e o valor dos elementos patrimoniais ativos identificados e avaliados, conforme mostrado na Tabela 9.

Tabela 9

Valor do goodwill ou fundo de comércio - $\$ 1,00$

\begin{tabular}{l|r}
\multicolumn{1}{c|}{ Especificação } & Valor \\
\hline Valor econômico da empresa & 101.762 \\
\hline (-) Ativos identificados e avaliados & $(94.796)$ \\
\hline Valor do goodwill ou fundo de comércio & $\mathbf{6 . 9 6 5}$ \\
\hline
\end{tabular}

Nota. Fonte: Elaborada pelo autor com dados modificados da empresa Gama.

8) Identificação e mensuração de dívidas e obrigações da empresa: foram confirmadas e estão expressas em valores da data da avaliação da empresa, conforme especifica a Tabela 10.

Tabela 10

Valor das dívidas e obrigações da empresa $-\$ 1,00$

\begin{tabular}{|c|c|}
\hline Especificação & Valor \\
\hline Passivo circulante & 25.263 \\
\hline Fornecedores a pagar & 15.372 \\
\hline Impostos a pagar & 9.891 \\
\hline Passivo não circulante & 26.811 \\
\hline Impostos parcelados & 9.432 \\
\hline Financiamentos a pagar & 17.379 \\
\hline Total & 52.074 \\
\hline
\end{tabular}

Nota. Fonte: Elaborada pelo autor com dados modificados da empresa Gama. 
9) Elaboração do balanço de determinação: esse procedimento consiste em demonstrar todos os bens e direitos, tangíveis e intangíveis, incluindo o valor do goodwill, bem como as dívidas e obrigações em valores atuais, base de cálculo da participação societária, conforme preconiza o novo Código de Processo civil brasileiro. A Tabela 11 apresenta os principais valores do balanço de determinação ou especial.

Tabela 11

Resumo do balanço de determinação ou especial - $\$ 1,00$

\begin{tabular}{l|r}
\multicolumn{1}{c|}{ Especificação } & \multicolumn{1}{c}{ Valor } \\
\hline Disponibilidades, créditos e estoque & 42.548 \\
\hline Realizável a longo prazo & 4.640 \\
\hline Investimentos & 12 \\
\hline Imobilizado & 47.596 \\
\hline Intangível (Goodwill) & 6.965 \\
\hline Total dos bens e direitos & $\mathbf{1 0 1 . 7 6 2}$ \\
\hline Total das dívidas e obrigações & $\mathbf{5 2 . 0 7 4}$ \\
\hline Situação líquida & $\mathbf{4 9 . 6 8 8}$ \\
\hline
\end{tabular}

Nota. Fonte: elaborada pelo autor com dados modificados da empresa Gama.

10) Determinação do valor das quotas ou lote de ações: o propósito da avaliação em estudo foi determinar o valor total da empresa, especificamente o novo valor da totalidade das quotas de capital, conforme especificado na Tabela 12.

Tabela 12

Novo valor das quotas de capital

\begin{tabular}{lr}
\hline \multicolumn{1}{c|}{ Especificação } & \multicolumn{1}{c}{ Valor } \\
\hline Ativos identificados e avaliados & 94.796 \\
\hline Goodwill & 6.965 \\
\hline Subtotal & 101.762 \\
\hline (-) Dívidas e obrigações & $(52.074)$ \\
\hline Novo valor das quotas de capital & 49.688 \\
\hline Nota. Fonte: elaborada pelo autor com dados modificados da empresa Gama.
\end{tabular}

Verifica-se que o novo valor das quotas de capital contém uma parcela relevante de $14 \%$, que se refere ao valor do goodwill. Desse modo, é verdadeiro afirmar que negócios lucrativos propiciam atrativa remuneração ao capital investido e ao mesmo tempo valorizam as participações societárias individuais.

\subsection{Análise dos resultados: aspectos objetivos na verificação de valor econômico de ativos intangíveis}

O esforço empregado nos cálculos anteriormente apresentados visou a reduzir o caráter subjetivo dos procedimentos que culminam no valor econômico da empresa. Coerentemente, a expressão monetária atribuída ao fundo de comércio ou goodwill decorreu de tratamentos contábeis e matemáticos. Envolveu primordialmente a receita de faturamento, os custos, despesas operacionais e os impostos pertinentes ao negócio especificamente.

O valor do goodwill agregado aos demais elementos patrimoniais da empresa Gama corresponde à parcela excedente que o negócio lucrativo é capaz de gerar, quando confrontado com o valor dos respectivos ativos necessários à consecução do negócio explorado. O número encontrado não dependeu de percepções qualitativas pessoais ou de visões de grupos de interesses. O método utilizou exclusivamente valores representativos da capacidade de geração de lucros, considerando fatores setoriais, variáveis econômicas e sociais nacionais, bem como contemplou o histórico de produção e vendas.

O processo de avaliação da empresa Gama não cogitou a individualização de valores concernentes aos atributos intangíveis, tais como nome comercial, marca, know how, localização 
privilegiada e equipe treinada. O posicionamento decorreu do desinteresse dos gestores por tal informação, considerando que os procedimentos para a alienação da empresa prescindiam dessa pormenorização. Contribuiu também para tal decisão o fato de os métodos de avaliação então disponíveis mostrarem-se essencialmente subjetivos e francamente discutíveis. Os atributos intangíveis são inter-relacionados e possuem dependência entre si, afirmam (Chareonsuk \& Chansa-ngavej, 2010). Nessas condições, tais elementos possuem valor pelo conjunto. Isoladamente perdem expressão monetária objetiva.

\section{CONCLUSÃO}

O propósito deste artigo foi discutir aspectos objetivos na determinação de valor econômico para os elementos intangíveis criados pela empresa. Foi realizado estudo de caso envolvendo empresa de capital fechado, de médio porte, que atua na área de autopeças. $O$ processo de avaliação da empresa Gama adotou duas abordagens tradicionais e fartamente conceituadas: abordagem dos ativos e abordagem da renda.

As providências concernentes à abordagem dos ativos compreenderam a avaliação dos elementos patrimoniais identificados. Envolveram bens e direitos tangíveis e intangíveis. Os imóveis foram avaliados a valores de mercado e as dívidas foram levantadas e valoradas a preços da data da avaliação da empresa. Tal tratamento atendeu plenamente ao que dispõem as leis brasileiras, no que se refere à avaliação de sociedades mercantis. Todavia, nessas condições, ficaria ausente a mensuração da expressão monetária dos elementos intangíveis criados pelo giro do negócio.

A abordagem da renda teve como objeto a determinação do valor do negócio, em que foi apresentada a expressão numérica correspondente à expectativa de lucros, benefícios e proveitos econômicos futuros. O resultado encontrado neste procedimento foi utilizado para determinar o valor do fundo de comércio ou goodwill, considerando que tal número somente pode ser encontrado de forma indireta, mediante a confrontação dos valores encontrados nas duas abordagens. Então, na avaliação pela metodologia do valor econômico, o valor do goodwill é uma diferença positiva decorrente do negócio lucrativo, cujo valor presente supera o valor dos bens e direitos identificados (Hendriksen \& Breda, 1992).

O estudo revelou que determinadas providências avaliatórias são essenciais para um adequado levantamento da expressão monetária do negócio. Referem-se ao exame crítico das receitas, custos, despesas e impostos, visando a refinar os números que se relacionam com o negócio em avaliação. Os relatórios contábeis naturalmente contêm valores que independem do negócio, tais como receitas não operacionais, indenizações judiciais, multas e honorários de advogados, dentre outros, que foram expurgados dos cálculos em discussão.

O conhecimento de indicadores de desempenho setoriais, perspectivas econômicas nacionais e do próprio planejamento estratégico da empresa em avaliação serviram para fundamentar estimativas de crescimento de faturamento.

A forma de avaliação adotada no caso da empresa Gama propiciou objetividade aos cálculos e valores encontrados porque foi determinada a partir de números relacionados diretamente com o negócio explorado. A expressão monetária do goodwill não dependeu de escores pessoais ou de conceitos representativos de grupos de interesses, exceto pelas estimativas do planejamento empresarial.

O valor econômico individual de elementos intangíveis, tais como nome, localização privilegiada, equipe treinada e know how, dentre outros, não foi objeto de cálculo, por desinteresse dos gestores. Além disso, as pesquisas indicam que tais elementos são interrelacionados e dependentes entre si para gerar vantagens e competitividade ao negócio.

Como sugestão para os próximos estudos propõe-se a aplicação da metodologia de avaliação pelo valor econômico em empresas que atuam em outras atividades econômicas, com o propósito de verificar sua aplicabilidade de forma geral. Também deveriam ser realizadas pesquisas visando à formulação de critérios objetivos de cálculo de expressão monetária individual dos elementos intangíveis criados pelo giro do negócio. 


\section{REFERÊNCIAS}

Axile-Ortiz, M. A. (2013). Perceiving the value of intangible assets in context. Journal of Business Research, 66, 417-424.

Chareonsuk, C., Chansa-ngavej, C. (2010). Intangible asset management framework: an empirical evidence. Industrial Management \& Data Systems, 110(7), 1094-1112.

Churyk, N.T., Mantzke, K.L. (2008). The relation between purchased goodwill and target characteristics. Academy of Accounting and Financial Studies Journal, 12(3), 19-18.

Clarkson, G. (2000). Intellectual asset valuation. Harvard Business School. 9 (-801-192), 1-23.

Comitê de Pronunciamentos Contábeis (2010). Pronunciamento Técnico CPC 04: Ativo Intangível. Brasília. $\quad$ Recuperado de http://static.cpc.mediagroup.com.br/Documentos/187_CPC_04_R1_rev\%2008.pdf

Damodaran, A. (2007), Avaliação de empresas (2a ed.). São Paulo: Pearson Prentice Hall.

Harris, R. S. (1997).Valuing companies: an overview of analytical aproaches. University of Virginia - Darden Business Publishing. UV0107. Charlottesville, VA.

Hawkins, D. F. (2002). Basic ratio analysis end equity valuation. Boston. Harvard Business School, 9,185-149.

Helfert, E. A. (2000). Técnicas de análise financeira: um guia prático para medir o desempenho dos negócios (9a ed.). Porto Alegre: Bookman.

Hendriksen, S. E., \& Breda, M. F. V. (1992). Accounting theory (5nd ed.) Illinois: Irwin.

Lei no 10.406, de 10 de Janeiro de 2002 (2002). Institui o código civil. Recuperado de http://www.planalto.gov.br/ccivil_03/Leis/2002/L10406.htm

Lei no 13.105, de 16 de Março de 2015 (2015). Institui o código de processo civil. Recuperado de http://www.planalto.gov.br/ccivil_03/_ato2015-2018/2015/lei/113105.htm

Leitner, P. (2005). Measure twice, cut once: creating and measuring value in the private firm. Strategic Finance, 87(3). 26-32.

Lorenz, D., \& Lützkendorf, T. (2008). Sustainability in property valuation: theory and practice. Journal of Property Investment \& Finance, 26(6), 482-521.

Luerhman, T. A. (2006). Note corporate valuation and market multiples. Boston. Harvard Business School, 9, 206-039.

Ornelas, M. M. G. (2003). Avaliação de sociedades: apuração de haveres em processos judiciais (2a ed.). São Paulo: Atlas.

Rabianski J. S. (1996). Going-concern value, market value, and intangible value. The Appraisal Journal, 64, 183-194.

Robert, M. J. (2006). Valuation concepts: evaluating opportunity. Boston. Harvard Business School Publishing.

Ross, S. A., Westerfield. W., \& Jaffe, J.F. (2007). Administração financeira (2a ed.). São Paulo: Atlas.

Sá, A. L. (2000) Ativo intangível e potencialidades dos capitais. Revista Brasileira de Contabilidade, 125, 46-53.

Santos, N. J. (2011). Metodologia para determinação do valor econômico de empresas de capital fechado em processos de apuração de haveres de sócio. Tese de Doutorado em Engenharia de Produção, Universidade Federal de Santa Catarina (UFSC), Florianópolis, SC, Brasil.

Verginis, C. S., \& Taylor, S. J. (2004). Stakeholders' perceptions of the DCF method in hotel valuations. Property Management, 22(5), 358-376. 
Watson, R. (2010) Small and medium size enterprises and the knowledge economy. Journal of Financial Regulation and Compliance, 18(2), 131-143. 